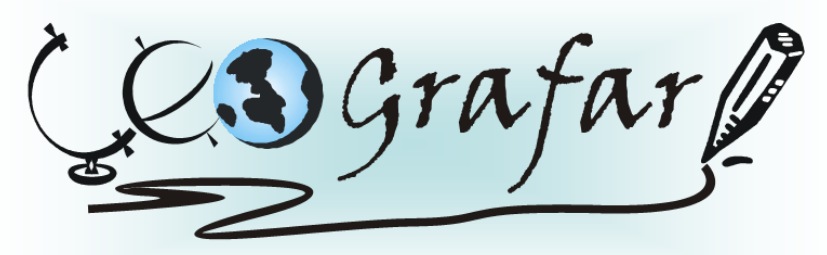

Revista Eletrônica do Programa de Pós-Graduação em Geografia - UFPR

\title{
UMA TEORIA GEOGRÁFICA PARA A ANÁLISE DA PRODUÇÃO SOCIOESPACIAL NAS CIDADES HISTÓRICAS TURÍSTICASS ${ }^{1}$
}

\author{
EVERALDO BATISTA DA COSTA ${ }^{2}$
}

FRANCISCO CAPUANO SCARLATO ${ }^{3}$

\begin{abstract}
Resumo: Diante da séria corrida pela mercantilização turística das cidades históricas brasileiras, este artigo tem por objetivo apresentar um aporte teórico-metodológico para a análise desta dinâmica que ronda o patrimônio cultural destas cidades, transformando-as em sua totalidade. Esse aporte está calcado em uma abordagem geográfica crítica no intuito de aguçar o espírito crítico e investigativo de pesquisadores que pretendam se debruçar sobre esses núcleos urbanos simbólicos da formação socioespacial brasileira, hoje, envolvidos pelo processo que denominamos dialética da construção destrutiva que enreda os bens culturais do mundo. Temos como objeto empírico para esta análise teórica e crítica, Diamantina, cidade da antiga zona do ouro e zona dos diamantes, em Minas Gerais, à qual nos dedicamos em pesquisa recente. Também nos são referenciais São João Del Rei, Tiradentes, Ouro Preto e Congonhas do Campo, as quais analisamos em anos anteriores.
\end{abstract}

Palavras- Chave: Valorização do Espaço; Território; Dialética da Construção Destrutiva; Cidade Histórica; Patrimônio Cultural.

\section{A GEOGRAPHICAL THEORY FOR THE ANALYSIS OF SOCIAL-SPACE PRODUCTION IN TOURISTIC HISTORIC CITIES}

\begin{abstract}
Given the serious race for the tourist merchandising of the brazilian historical cities, this article aims to provide a theoretical-methodological contributions for the analysis of this dynamic that round the cultural heritage of these cities, transforming them in its entirety. This contribution is based on a critical geographical approach in order to sharpen the critical spirit and researchers' investigative that intend to work on these symbolic urban centers of the brazilian social-space's formation, today, we call the process involved destructive dialectic of construction which involves the world's cultural property. We object to this analysis for empirical and theoretical criticism, Diamantina, city of the old zone of the gold and diamonds in Minas Gerais, to which we devote to recent research. References are also in São João del-Rei, Tiradentes, Ouro Preto and Congonhas do Campo, which analyzed in previous years. Keywords: Space Valorization; Territory; Destructive Dialectic of Construction; Historical City; Cultural Heritage. INTRODUÇÃO
\end{abstract}

\footnotetext{
${ }^{1} \mathrm{O}$ presente texto sintetiza nossa análise desenvolvida, na perspectiva da geografia urbana, ao longo dos últimos seis anos, que nos dedicamos às cidades históricas de Minas Gerais (Tiradentes, São João Del Rei, Ouro Preto e Diamantina - nos cursos de graduação e pós-graduação em Geografia da Universidade de São Paulo - USP).

${ }^{2}$ Mestre, bacharel e licenciado em Geografia pela Universidade de São Paulo (USP). Professor da Faculdade Politécnica de Jundiaí - SP (FPJ - UNIANHANGUERA) e da Faculdade Santa Izildinha de São Paulo (FIESI).

${ }^{3}$ Professor Doutor do Departamento de Geografia da Universidade de São Paulo - USP.
} 
Inquieta-nos o entendimento de que algumas cidades históricas brasileiras estão passando por um processo de reapropriação estratégica de seus espaços centrais, dotados de uma materialidade de significativo valor histórico-cultural, onde agentes públicos e privados somam forças no acelerado processo de mercantilização do patrimônio cultural, de forma imediatista, classista, descompromissada e não participativa. As análises das ações que se estabelecem em cidades históricas como São João Del Rei (COSTA, 2008), Tiradentes (COSTA, 2008a), Ouro Preto (CIFELLI, 2005), Recife (LEITE, 2004) e em curso em Diamantina (COSTA, 2008b, 2009), em nome da dinamização da atividade turística, mostram que há o descumprimento de diretrizes e normas das cartas patrimoniais de preservação dos bens culturais, sobretudo no que diz respeito ao Patrimônio Cultural da Humanidade, consagrado por meio da Convenção Relativa à Proteção do Patrimônio Mundial Cultural e Natural, adotada na década de 1970, pela Organização das Nações Unidas para a Educação, a Ciência e a Cultura (UNESCO, 1972), que reconhece o valor excepcional universal dos bens culturais do mundo. ${ }^{4}$ Em Minas Gerais, Diamantina, Ouro Preto e Congonhas do Campo representam, pelo reconhecimento da UNESCO (Organização das Nações Unidas para a Educação, a Ciência e a Cultura), Patrimônio Cultural da Humanidade.

\footnotetext{
4 “As instituições previstas na Convenção Relativa à Proteção do Patrimônio Mundial, Cultural e Natural, compõem a estrutura de uma autoridade internacional de proteção, cuja função principal é conferir plena execução à própria Convenção, promovendo a inscrição de bens culturais na Lista do Patrimônio Mundial ou na Lista do Patrimônio Mundial em Perigo e prestando assistência internacional." (SILVA, 2003, p. 77). Essa autoridade internacional representa-se por meio de um órgão executivo permanente, o Comitê do Patrimônio Mundial, integrado por um Comitê consultivo composto por representantes do ICCROM (Centro Internacional de Estudos para Conservação e Restauração dos Bens Culturais, organização ligada à restauração dos bens culturais, criada pela UNESCO, em 1951, durante sua $6^{a}$ Conferência-geral / ver: www.iccron.org) e do ICOMOS (Conselho Internacional de Monumentos e Lugares de Interesse Artístico e Histórico, organização não governamental fundada em 1965, fruto das diretrizes do Congresso de Veneza, de 1964; promove a teoria, a metodologia e a tecnologia aplicadas na conservação e proteção do patrimônio arquitetônico / ver: www.internationalicomos.org/e_statut.htm.). Ainda há um fundo internacional, paralelamente às ações do Comitê, para recolher e distribuir os recursos necessários para financiar as ações protetoras. A análise do original da Convenção esclarece-nos em seu Artigo 8 que, "le Comitê du patrimoine mondial (...) est composé de 15 Etats parties à la convention, élus par les Etats parties à la convention réunis em assemblée générale (...) Le nombre des Etats membres du Comitê será porté à 21 à compter de la session ordinaire de la Conférence générale qui suivra l'entrée em vigueur de la presente convention pour au moins 40 Etats." (UNESCO, 1972, p. 04).
} 
Entendendo que a refuncionalização ${ }^{5}$ do patrimônio para o turismo, nas cidades históricas, o faz adquirir valor de mercado, acreditamos que pode ocorrer um descompromisso com o passado, com o lugar e com as pessoas, através da tendência global e do próprio turismo de criar um ambiente propício à mundialização desses lugares, de todos os valores, relações e da própria cultura, transformando-a em um novo gênero de mercadoria. Consideramos que essa dinâmica deve ser apreendida para além do mero olhar, mas próxima de uma observação pertinente e coerentemente crítica, uma vez que a gestão dos centros históricos, patrimônio cultural local, vem ocorrendo de forma unilateral, imediatista e descompromissada pelos agentes públicos e de mercado, de forma associada.

Logo, nosso objetivo é apresentar um aporte teórico-metodológico para a análise da produção do espaço pelo turismo nos núcleos urbanos tombados brasileiros, especialmente aos núcleos consagrados internacionalmente como Patrimônio Mundial (UNESCO, 1972) frente à tendência fetichizante da chamada "indústria cultural" por meio do turismo; um processo dialético de "construção" / "desconstrução" vivenciado por cidades como Diamantina e Ouro Preto, no interior do estado de Minas Gerais, ao integrarem a Lista do Patrimônio Mundial, que hoje é enredada pela busca crescente da chancela da UNESCO. ${ }^{6}$

Estabelece-se, nos núcleos urbanos tombados, através do turismo, uma relação entre antigas formas e velhos usos, com novas formas e funções, perfazendo a interação do lugar com o mundo que o atravessa com novos costumes, mercadorias, valores, hábitos e relações. Nesse contexto, acreditamos que a teoria geográfica do espaço (produção e valorização do espaço), pode contribuir para uma melhor compreensão da cidade histórica como espacialidade formada

\footnotetext{
${ }^{5}$ Concordamos com Luchiari (2005, p. 96) ao enfatizar que a apropriação dos bens culturais vem seguindo a conduta de transformação do patrimônio cultural em mercadoria, assim como a sua refuncionalização vem servindo, agora, à ideologia do consumo e não mais às práticas culturais representativas do sentimento de pertencimento das culturas e populações locais.

${ }^{6} \mathrm{O}$ procedimento de inscrição de um bem na lista do Patrimônio Mundial demanda duas fases distintas. Na primeira, o Estado interessado inventaria o bem cultural e aplica as medidas necessárias para sua proteção. Na segunda, a solicitação da inscrição do bem cultural é submetida ao exame e à deliberação do ICOMOS (Conselho Internacional de Monumentos e Lugares de Interesse Artístico e Histórico), cujo comitê defere ou rejeita a proposta de inscrição do bem (Silva, 2003). No caso de Diamantina, foi proposta pelo governo federal por intermédio do Ministério das Relações Exteriores mediante dossiês encaminhados ao ICOMOS, instruídos com o nome do patrimônio e dos bens que o constituem, sua localização geográfica, as medidas de proteção e a justificativa de seu "valor universal excepcional". A repartição dos bens culturais e naturais na Lista do Patrimônio Mundial pode ser analisada em UNESCO (2007a).
} 
perpassada pelo que denominamos dialética da construção destrutiva (COSTA, 2008b) quando apropriada pela atividade do turismo. Essa dialética representa o jogo simultâneo, relacional e contraditório da "preservação" / "mercantilização" que se dá em nome de um turismo que fragmenta e pulveriza a sociedade e o lugar, ao seguir a lógica contraditória de reprodução do capitalismo, como identificamos em Diamantina. São ações que transformam a realidade local e produzem espaços sociais diversificados, onde o velho e o novo fundem-se dando lugar a uma nova organização socioespacial nas cidades históricas turísticas - núcleos urbanos simbólicos no bojo da "formação socioespacial" (SANTOS, 2004) brasileira, hoje, eleitos pelo capital seletivo, em nome do chamado turismo cultural.

Nesse sentido, atendendo ao objetivo deste artigo, apresentaremos o aporte teóricometodológico com o qual sustentamos nossas pesquisas voltadas para a análise crítica da produção do espaço urbano quando da mercantilização desenfreada do patrimônio cultural em Diamantina e outras cidades do sertão mineiro, como Tiradentes, Ouro Preto e Congonhas do Campo.

\section{APORTE TEÓRICO-METODOLÓTICO PARA UMA ABORDAGEM CRÍTICA À MERCANTILIZAÇÃO TURÍSTICAS DAS CIDADES HISTÓRICAS}

Nas ciências em geral e em especial nas ciências humanas, são criadas palavras e expressões para dar sentido a categorias e conceitos abstratos que passam a fazer parte do repertório apropriado para a produção do conhecimento nas mais variadas áreas. Aqui, interessanos a Geografia, que cria uma linguagem científica específica que vai caracterizá-la. Devemos considerar que essa criação não é desordenada ou descompromissada com os verdadeiros sentidos dos termos. Assim, reconhecemos que a categoria central da reflexão feita em nossa disciplina é o espaço geográfico e sua definição, no tempo atual, vai estruturar nossa discussão. Nesse sentido, delimitaremos a noção das categorias de análise "espaço" e também "território", empregados largamente pela Geografia e que podem nos auxiliar a compreender as novas dinâmicas que envolvem os núcleos urbanos tombados com o turismo; dinâmicas, hoje, catalisadas pela chamada "indústria cultural", enquanto um processo de intensa mercantilização das formas culturais (THOMPSON, 1995). 
A escolha exata de um método fornece elementos para a elaboração de um plano de trabalho e seu encaminhamento. Segundo Moraes e Costa (1996), propicia um critério de relevância na seleção dos temas a serem abordados nas condições de repensar a Geografia à luz de um parâmetro sólido, sustentado numa interpretação da realidade que transcende e engloba a própria disciplina.

Como assumimos uma postura crítica, concordamos que é na dialética da negação e da assimilação, que a crítica válida é a que introduz a nova afirmação (MORAES e COSTA, 1996), onde o método fornece o próprio balizamento da discussão, pois introduz categorias que nos ajudam a compreender a realidade.

É nesse contexto que introduzimos um aporte teórico-metodológico para a compreensão das novas dinâmicas que favorecem a produção capitalista do patrimônio cultural e dos núcleos urbanos tombados brasileiros, onde o movimento entre as categorias "espaço" e "território" deve permear toda a análise. Logo, o aporte teórico-metodológico do qual nos valemos, que é a base da reflexão proposta é, principalmente, a análise marxista desenvolvida por David Harvey e pelo geógrafo brasileiro Milton Santos em algumas de suas obras, além de trabalhos de outros estudiosos influenciados por ele, como Antônio Carlos Robert Moraes.

Assim, como o patrimônio cultural, hoje, no Brasil, vem sendo transformado em um produto econômico da "indústria cultural", uma nova mercadoria que entra no circuito internacional do turismo, uma mercadoria consumida por platéias cada vez maiores, revestida por uma embalagem e um conteúdo adequados para a venda, acreditamos que a crítica à sua mercantilização deve se fundamentar em um posicionamento metodológico que envolva a lógica dialética dos pares (uso / troca) e ("preservação" / "mercantilização"). A análise geográfica do processo de transformação do uso em troca, dessa maneira, obriga-nos a discorrer sobre a "produção" e "valorização do espaço" (MORAES, 2005; SANTOS, 2002), de acordo com a atual dinâmica do capitalismo.

Dessa maneira, a proposta metodológica é a de se analisar as transformações do espaço urbano (da cidade histórica enquanto totalidade) - fruto de um longo "processo histórico" (SANTOS, 2002) - a partir do movimento dialético do uso e da troca, reconhecendo os processos de "valorização do espaço" (MORAES, 1996, 2005) que criam critérios de especialidade, 
singularidade, originalidade e autenticidade em cidades como Diamantina, de forma seletiva e pontual em relação à totalidade mundo. "Valorização do espaço" que coloca em evidência as contradições das ações que permeiam a sociedade contemporânea de um mundo globalizado; o que esboça o próprio método histórico-dialético no sentido que, hoje, os bens culturais materiais (e imateriais) são envolvidos pela unidade indissolúvel dos opostos: "preservação" / "mercantilização".

Logo, sobre o método histórico-dialético, posicionamo-nos com Kosik (1976), para quem a dialética trata da "coisa em si". Mas a "coisa em si" não se manifesta imediatamente ao homem, segundo o autor. Para chegar à sua compreensão, é necessário fazer não só certo esforço, mas também um détour. Por este motivo o pensamento dialético distingue entre representação e conceito da coisa, com isso não pretendendo apenas distinguir duas formas e dois graus de conhecimento da realidade, mas, especialmente e, sobretudo, sobre a práxis humana. A atitude primordial e imediata do homem, em face da realidade, não é a de um abstrato sujeito cognoscente, mas de uma mente pensante que examina a realidade especulativamente, porém a de um ser que age objetiva e praticamente, de um indivíduo histórico que exerce a sua atividade prática no trato com a natureza e com os outros homens, buscando atender a consecução dos próprios fins e interesses dentro de um conjunto de relações sociais (KOSÍK, 1976).

Consideramos esse método de abordagem o mais apropriado para a apreensão da cidade histórica enquanto objeto empírico e total, para se adentrar num debate caro à Geografia, que é a questão da mercantilização de patrimônio cultural através do desenvolvimento do turismo, de forma que esses núcleos urbanos tombados são inseridos no circuito global de competição entre as cidades, tendo como suporte relevante as novas técnicas, a informação e a valorização simbólica e econômica do patrimônio cultural. Essa abordagem pode nos auxiliar no desvendamento das novas espacialidades das relações sociais produzidas num ritmo diverso de outrora, nesses núcleos urbanos; particularmente, pode nos levar às evidências da contradição do processo de "preservação" / "mercantilização" do patrimônio cultural, refletidas através da (re)produção do espaço urbano em cidades históricas como Diamantina, Ouro Preto e Congonhas do Campo, elevadas à categoria de Patrimônio Cultural da Humanidade pela UNESCO, em Minas Gerais. 
O diagrama abaixo sintetiza o aporte teórico-metodológico proposto, o qual esboçaremos de forma pormenorizada, em seguida.

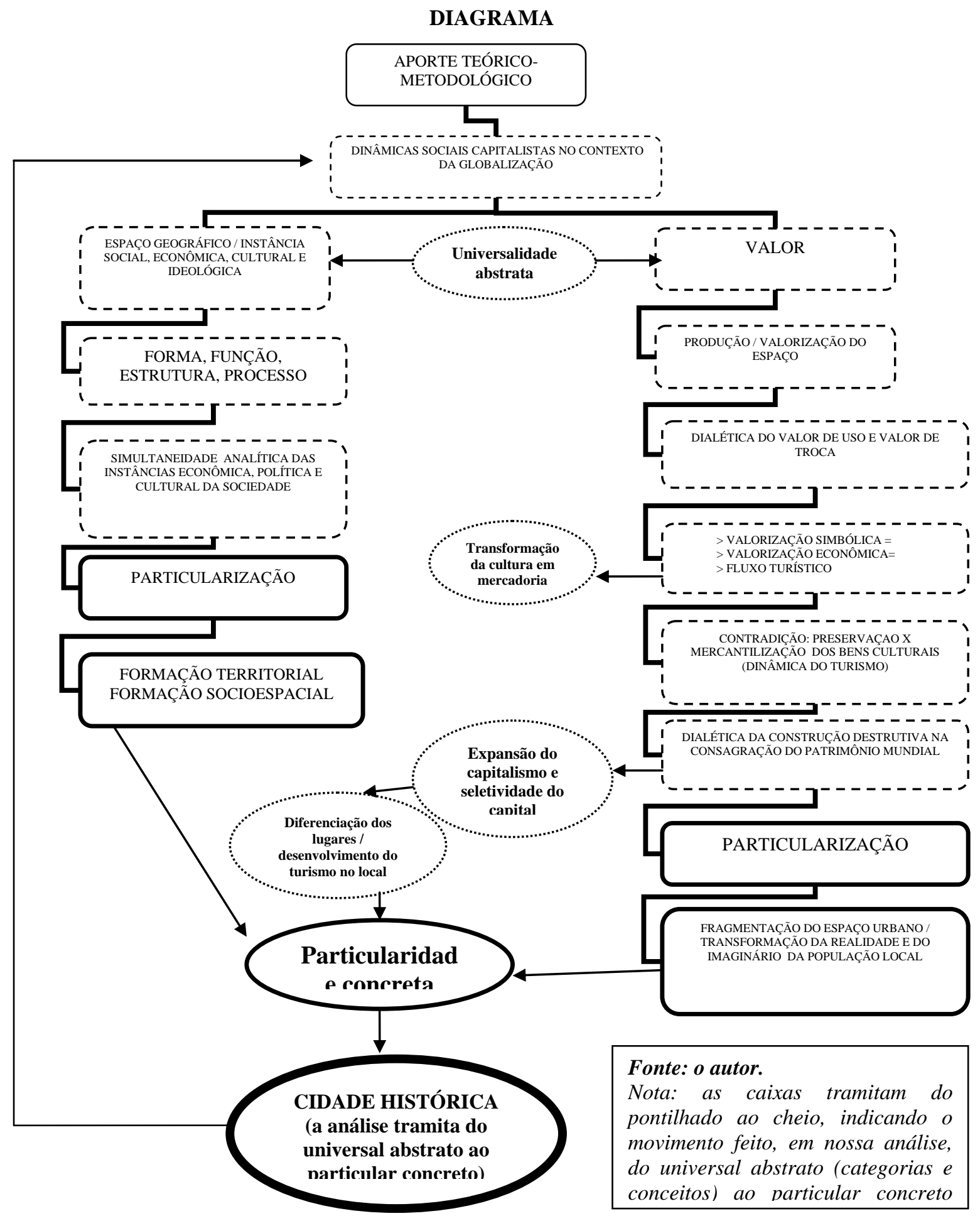




\section{VALORIZAÇÃO DO ESPAÇO E FORMAÇÃO TERRITORIAL}

Partimos do entendimento de que a geografia humana é uma ciência social comprometida com a análise da apropriação da natureza e consequiente produção do espaço pelo homem. Para Moraes (2000), esse processo é passível de ser identificado num corte ontológico do real, ou seja, manifesta-se na realidade com determinações específicas, atuando como um elemento particularizador. A produção do espaço é um processo que resulta do trabalho humano, que é um ato de incorporação e criação de valor, de acordo com Moraes (2000), concluindo que a formulação categorial mais precisa para expressá-lo, na Geografia, deva ser a da "valorização do espaço". 7

Como não encontramos uma definição única para a categoria "espaço" no âmbito das ciências, cabe aqui, inicialmente, frisarmos que tratamos de um espaço do homem, de um espaço social, ou seja, do espaço geográfico, que segundo Santos (2004a), deve ser considerado como um conjunto de relações sociais realizadas através de formas que se apresentam como testemunhos de uma história escrita por processos do passado e do presente, ou seja, o espaço se define como um conjunto de formas que representam relações sociais do passado e atuais, e por uma estrutura representada por relações sociais que estão acontecendo "diante de nossos olhos" e que se manifestam por processos e funções. " ${ }^{8}$ "O espaço é, então, um verdadeiro campo de forças cuja aceleração é desigual” (SANTOS, 2004, p.153).

\footnotetext{
${ }^{7}$ Para Smith (1976 apud Harvey, 1980, p.131), a palavra valor tem dois significados diferentes; algumas vezes expressa a utilidade de algum objeto particular, e outras, o poder de compra de outros bens que a posse daquele objeto transmite. O primeiro, "valor de uso", o segundo, "valor de troca". O autor esclarece que as coisas de grande valor de uso têm, freqüentemente, pequeno ou nenhum valor de troca; e ao contrário, as de grande valor de troca têm, freqüentemente, pequeno ou nenhum valor de uso. Para nós, a palavra "valor" suscita não dois, conforme referencia Smith (op. cit.), mas três significados. Consideraremos um terceiro sentido dessa palavra, o simbólico, o qual aparecerá ao longo da pretendida pesquisa; valor simbólico que atribuímos aos objetos, algumas vezes com o sincero objetivo de preservação de nossa identidade ou da memória, outras com o objetivo de se agregar valor econômico ao objeto via avultamento do próprio valor simbólico, o que muitas das vezes acaba por metamorfosear seu real simbolismo. Demonstramos, com isso, a importância de não nos atermos a uma abordagem materialista da cidade (SCARLATO, 2005), mas tentaremos entender como a criação de um "capital simbólico" (HARVEY, 2005) contribui para a "ultravaloração" econômica do espaço urbano por meio do turismo, ou seja, a dialética do valor de uso e do valor de troca tem na valorização simbólica um adendo para se produzir marcos de distinção, novas mercadorias criadas pela "indústria cultural" para o desenvolvimento turístico.

${ }^{8}$ Adotamos a proposta de análise oferecida por Milton Santos, que considera relevante o estudo do espaço geográfico a partir dos quatro termos disjuntivos - forma, função, estrutura e processo -, pois entendemos que interpretar a evolução e organização de um espaço dotado de objetos remanescentes de outros períodos históricos, significa remontarmos ao início do processo de produção desse patrimônio, que enquanto formas, possuíam
} 
Dessa forma, reconhecemos a categoria espaço como uma instância da sociedade, ao mesmo tempo em que a instância econômica e a instância cultural ideológica, de acordo com Santos (1986). O autor deixa claro que o espaço contém essas instâncias e essas instâncias o contêm. Nos dizeres de Santos (1986, p.05),

A economia está no espaço, assim como o espaço está na economia. O mesmo ocorre com o político-institucional e com o cultural-ideológico. Isso quer dizer que a essência do espaço é social. Nesse caso, o espaço não pode ser formado unicamente pelas coisas, os objetos geográficos, naturais ou artificiais, cujo conjunto nos oferece a natureza. $\mathbf{O}$ espaço é tudo isso mais a sociedade: cada fração da natureza abriga uma fração da sociedade atual. (tradução e grifo nossos).

Nesse sentido, o que analisamos são as relações pelas quais a sociedade se estabelece no seu espaço, ou seja, analisamos a sociedade a partir da dimensão espacial, quer dizer, identificamos a produção, reprodução e o que denominamos dialética da construção destrutiva no espaço através das espacialidades da vida social, que em Diamantina são representadas pelo antagonismo das ações dirigidas ao centro histórico em contraposição aos bairros mais carentes das cidades, ações que revaloram seus bens culturais em prol do desenvolvimento do turismo e produzem uma cidade dual.

Devemos ter claro que o turismo urbano representa a quase totalidade dos fluxos turísticos mundiais, sendo que as cidades não são apenas núcleos emissores de turistas, mas também pólos receptores de intensos fluxos (CRUZ, 2003), o que se dá, em nosso entender, pelo fato de a incessante busca do lucro, às vezes da renda de monopólio (HARVEY, 2005), impor a procura ou o estabelecimento de critérios de especialidade, singularidade, originalidade e autenticidade nos lugares; daí Scifoni (2003, p. 08) afirmar que "a corrida para a inscrição na Lista do Patrimônio Mundial tem uma explicação: estar na Lista significa contar com um status internacional, prestígio e reconhecimento que é fundamental para o marketing do turismo."

Estar na Lista do Patrimônio Mundial representa, para muitos países, a inserção de seus bens culturais na mundialização dos lugares, no circuito global de cidades, através da atividade turística, que requer a acumulação e reafirmação tanto de um "capital simbólico" (HARVEY,

determinadas funções dentro de uma estrutura colonial, sendo refuncionalizados e reestruturados na contemporaneidade, para atenderem a outras necessidades e atividades humanas, como o turismo. 
2005) como de marcos de distinção. O que se identifica é que a partir da inscrição na Lista, promove-se um bombardeio de imagens "valorativas" que produzem simulacros da história, da tradição e da cultura local, onde o marketing, a respeito de realizações artísticas relacionadas a esses valores, presta um apoio necessário à formulação desse processo de valorização espacial; coroa-se, dessa maneira, o encontro da economia com a cultura, da "mercantilização" e da "preservação", nos lugares, como identificamos em Diamantina, inserida, atualmente, no circuito internacional do turismo.

A sociedade e sua dimensão espacial podem ser interpretadas através da espacialidade da política, da economia e da cultura. Uma abordagem da espacialidade da economia força-nos a discorrer sobre a "valorização do espaço"; a espacialidade da política, que remonta a poder, dirige a análise para a questão da "dominação do espaço"; já a espacialidade da cultura, que se estabelece enquanto espaço da consciência, exige uma abordagem sobre a "representação do espaço". Dessa maneira, seja através da valorização do espaço, da dominação do espaço ou da representação do espaço, o que pretendemos frisar é que esse contexto acaba por particularizar, exigindo um método de análise numa perspectiva histórica que, no limite, redunda no reconhecimento da formação territorial, com uma ênfase política que articula valorização e representação (identificamos, assim, que as três análises caminham juntas, representam simultaneidade), ou seja, compreendemos que o entendimento da sociedade não se restringe ao âmbito da política, da economia ou da cultura, mas na imbricação das três abordagens para o melhor entendimento das espacialidades sociais, da realidade em diferentes momentos históricos. ${ }^{9}$

\begin{abstract}
Assim, enquanto a valorização do espaço aparece como o horizonte teórico genérico de indagações da geografia proposta, a formação territorial desenha-se como o objeto empírico da pesquisa, o ajuste de foco naquela ótica angular de captar o movimento histórico própria (sic) da geografia humana. Uma abordagem que busca apreender a valorização do espaço em manifestações únicas sincronicamente analisadas, logo, em processos de formação de territórios singulares. Transita-se, assim, da vaguidade da categoria "espaço" ao preciso e objetivo conceito de "território" (...) E nesse, ou melhor, em sua construção, às determinações mais especificamente econômicas se associam as injunções do universo da política e da cultura. (MORAES, 2000, p. 47).
\end{abstract}

\footnotetext{
${ }^{9}$ Esse método de abordagem foi discutido em aula proferida pelo Prof. Dr. Antônio Carlos Robert Moraes, aos alunos do Programa de Pós-Graduação em Geografia Humana, no Departamento de Geografia da USP, no dia 25 de setembro de 2007; disciplina: Formação Territorial e Teoria em Geografia Humana.
} 
Moraes (2000) esclarece que toda sociedade para se reproduzir cria formas, duráveis ou não, sobre a superfície da terra. São formas que representam necessidades, desejos, angústias e medos, que respondem ao ordenamento socioeconômico, político e cultural do grupo que as constrói. ${ }^{10}$ Normas são estabelecidas, nesse processo, que acabam por regular o uso do espaço produzido socialmente e dos recursos naturais inerentes a ele. Nesse sentido, identificamos que o espaço é produzido por toda a sociedade, mas dirigido por alguns, coordenado e normatizado por uma minoria que representa a sociedade, ou ao menos deveria fazê-lo.

Isso reflete, como aponta Cruz (2007, p. 10), a mais importante contradição do modo de produção capitalista no que tange ao espaço: "mesmo sendo produzido socialmente, sua apropriação é privada", seria uma ingenuidade teórica acreditar que todos os indivíduos que habitam o planeta participam da mesma forma e com a mesma intensidade dos processos de produção do espaço. Há que se distinguir atores hegemônicos e não hegemônicos ou os principais produtores do espaço.

Assim, entendemos que um espaço produzido historicamente, herança que condiciona a apropriação e os usos dos lugares, pode representar uma reserva de valor ao propiciar uma refuncionalização para o turismo, com a implantação de novas relações e práticas sociais, permeadas por novos desejos e necessidades que acabam por dar continuidade histórica, formal e estrutural ao espaço, bem como a permanência da sociedade; processo incipiente e evidente em Diamantina, através da análise das atuais ações voltadas à "venda" de seu patrimônio (Foto 01).

Pelo exposto, concordamos com Moraes e Costa (1996, p.121) e reconhecemos o território como processo histórico e social, isto é, dotado de sentido pela ação dos homens, o que não pode ser confundido com a concepção de espaço natural. Nesse ponto, os autores verificam uma dialética entre valor criado (valor no espaço) e valor contido (valor do espaço), dialética essa que favorece o alcance da concretude na compreensão do território se historicizarmos permanentemente sua análise, "os processos territoriais aparecem como momentos da totalidade".

\footnotetext{
${ }^{10}$ Segundo Moraes (2000), as formas produzidas expressam uma quantidade de valor (trabalho morto) incorporado ao solo "- substantivam na paisagem (congelam, em certo sentido) relações sociais específicas." (p.33).
} 


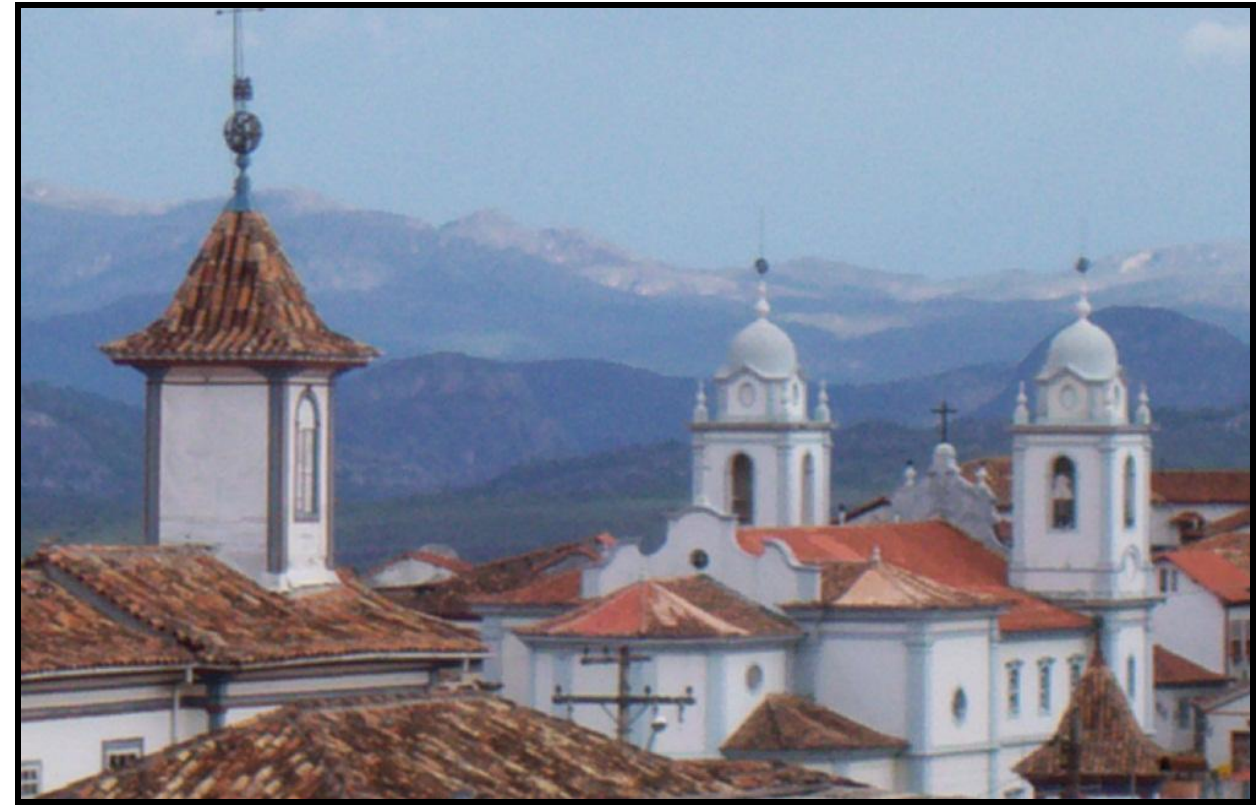

Os autores supracitados definem o "valor no espaço" como aquele criado pelo trabalho, onde o espaço torna-se o receptáculo da produção material, de forma que a diferenciação do trabalho acumulado sobre áreas distintas define o valor real. Assim, a produção instala-se no espaço valorizando nesse a localização e a distância; “é um valor criado”, segundo os autores. Contudo, torna-se relevante em nossa abordagem o "valor do espaço", enquanto um valor que é transferido aos objetos durante sua criação ou enquanto um valor que é atribuído a objetos préexistentes; o "valor do espaço" é transferido no processo de trabalho para o produto "através das características próprias de cada lugar” (MORAES e COSTA, 1996, p.122), o que ocasiona uma heterogeneidade na produção e apropriação dos lugares, onde singularidades são estabelecidas através do trabalho humano; o que identificamos é a atribuição de valores distintos a estruturas socioespaciais distintas, em nome do desenvolvimento turístico. ${ }^{11}$

\footnotetext{
${ }^{11}$ A valorização diferencial do espaço produz e reproduz ao mesmo tempo em que fragmenta e destrói, ocasionando disparidades socioespaciais, hoje, induzidas, também, pela valorização de singularidades, excepcionalidades e "capital simbólico" evidenciados no espaço por meio de novas estratégias do capital, processo claramente identificado em Diamantina, através das novas estratégias de apropriação do patrimônio cultural local para o desenvolvimento do turismo.
} 
Em síntese, tratamos da questão da "valorização", pois - objetivada pelo trabalho humano implica criação e apropriação de valores, produzindo e reproduzindo o espaço geográfico. Esse movimento se dá através de riquezas naturais que são transformadas em objetos de uso e de consumo $^{12}$, que, enquanto formas construídas, se agregam ao solo sobre o qual estão erguidas, isto é, trabalho materializado na paisagem, valor depositado em lugares, conforme Moraes (2005). Esse autor aponta-nos que é em função disso que os lugares passam a se diferenciar por características humanas e não apenas por condições naturais variáveis. No entanto, acreditamos que a valorização espacial se aproxima, sobretudo hoje, da construção de um "capital simbólico" (HARVEY, 2005) sobre o "sistema de objetos" (SANTOS, 2002) espacial, que ganham novos sentidos, são revalorados, ocasionando novas espacialidades, novas distinções através da "ultravaloração" do espaço. Assim, forja-se o "valor do espaço" (MORAES e COSTA, 1996), teoria aplicável no caso da atual dinâmica que permeia a questão da apropriação estratégica de núcleos urbanos tombados pelo turismo, que ressignifica o patrimônio cultural; onde esse, através do simbolismo do qual é investido, torna-se matéria-prima da "indústria cultural" em prol do desenvolvimento do turismo, uma atividade que tende a fragmentar a cidade histórica enquanto totalidade devido a sua lógica espacial seletiva. Acreditamos que, no caso específico de Diamantina, sua consagração como Patrimônio Cultural da Humanidade constitui um "evento" (SANTOS, 2002, p. 143) ${ }^{13}$ tributário da valorização do espaço urbano, na atualidade, cujas ações favorecem a produção de uma cidade dual, dialeticamente fragmentada e articulada, onde a

\footnotetext{
${ }^{12}$ Harvey (1980) discorre longamente sobre a distinção entre valor de uso e valor de troca na sua forma original, esclarecendo que o debate clássico ainda pode prover esclarecimentos a respeito das problemáticas urbanas contemporâneas. Karl Marx usa os termos (valor de uso e valor de troca) de forma relacional e dialética; de maneira que, isoladas, não possuem significado em si próprias. Para Marx, esses valores só passam a existir, ganham significado, através do relacionamento entre si. A utilidade de uma coisa faz dela um "valor de uso" que só se realiza com a utilização ou consumo, que no limite, essas coisas enquanto "valor de uso" são veículos materiais do "valor de troca", é nesse sentido que entendemos a dialética marxiana do valor de uso e do valor de troca. "Como valores-deuso as mercadorias são de qualidades diferentes; como valores-de-troca só se diferem na quantidade, não contendo valor-de-uso" (Marx, 1982, p.44). A análise de Harvey (1980) possibilita-nos entender que a expressão "valor de uso" pode ser aplicada a toda classe de objetos, atividades e eventos em situações particulares, sociais e naturais. Pode se referir à ideologia religiosa, instituições sociais, trabalho, linguagem, mercadorias, recreação etc. "é razoável considerar o valor de uso do conceito "valor de uso"” (HARVEY, 1980, p. 132). Essa análise simboliza a importância da luta para a permanência dos usos em detrimento da troca e não o contrário, faz-nos acreditar que a atual transformação do espaço do cidadão em mera mercadoria pode representar o caminho para o colapso de um sistema dinâmico e complexo, que é a cidade, em especial, a cidade histórica.

${ }^{13}$ Consideramos o conceito de "evento" proposto por Milton Santos. Para o autor, um evento é, simultaneamente, a matriz do tempo e do espaço; um evento não se repete, são, pois, todos novos. Na verdade, os eventos mudam as coisas, transformam os objetos, dando-lhes, ali mesmo onde estão, novas características. "Os eventos são idéias e não apenas fatos. Uma inovação é um caso especial de evento, caracterizada pelo aporte a um dado ponto, no tempo e no espaço, de um dado que nele renova um modo de fazer, de organizar ou de entender a realidade".
} 
Revista Geografar

Curitiba, v.3, n.2, p.34-58, jul./dez. 2008 www.ser.ufpr.br/geografar

ISSN: 1981-089X

"valorização" do centro histórico parece depender do processo de "precarização" da periferia (Foto 02 e Foto 03).

FOTO 02: BAIRRO RIO GRANDE, DE OCUPAÇÃO DESORDENADA, NO ENTORNO DO CENTRO HISTÓRICO DE DIAMANTINA, COM GRAVÍSSIMOS PROBLEMAS DE INFRA-ESTRUTURA URBANA. AS CASAS FORAM CONSTRUIIDAS EM MEIO ÀS PEDRAS. FOTO DO AUTOR / FEV. 2008.

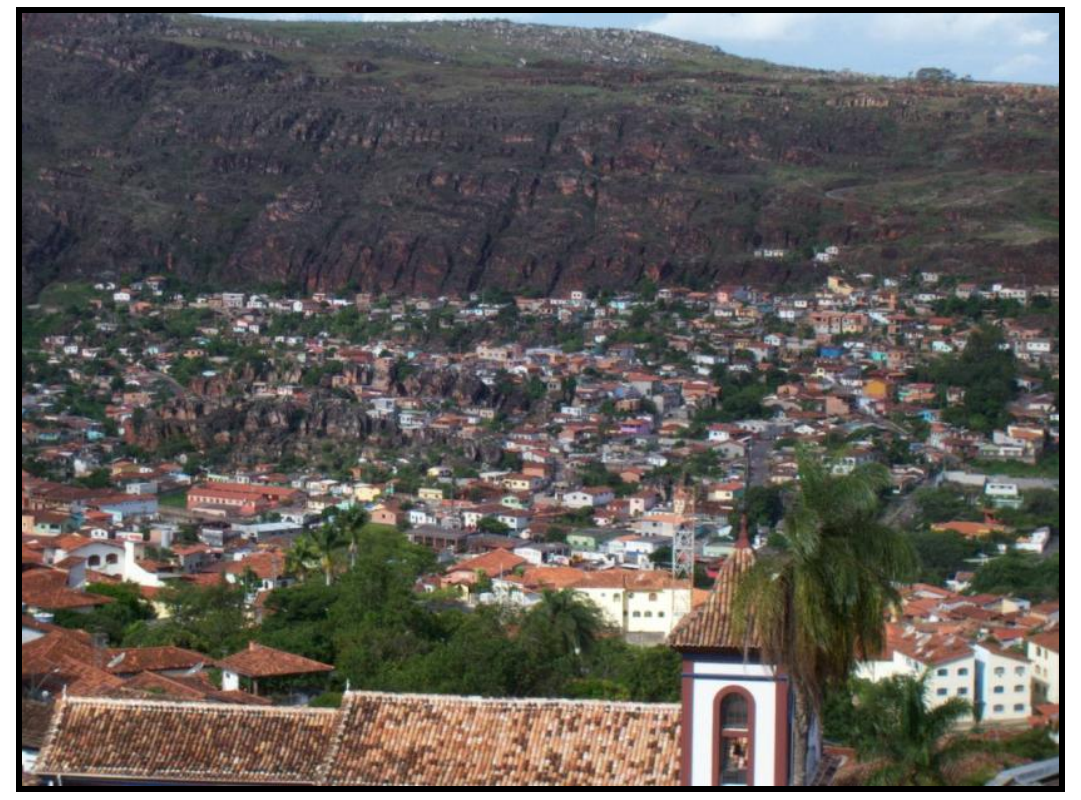

FOTO 03: HABITAÇÕES PRECÁRIAS, ENTRE AS PEDRAS, NO BAIRRO RIO GRANDE, EM DIAMANTINA, ESBOÇANDO O DESCASO PÚBLICO COM A PERIFERIA DA CIDADE, FRENTE A VALORIZAÇÃO ESPACIAL CONCENTRADA NO CENTRO HISTÓRICO. ISSO REPRESENTA UMA AÇÃO FRAGMENTADA E SEGREGACIONISTA SOBRE A CIDADE, APRESENTANDO UM PLANEJAMENTO QUE SE FAZ AOS FRAGMENTOS, DE FORMA ELITIZADA. FOTO DO AUTOR / FEV. 08.

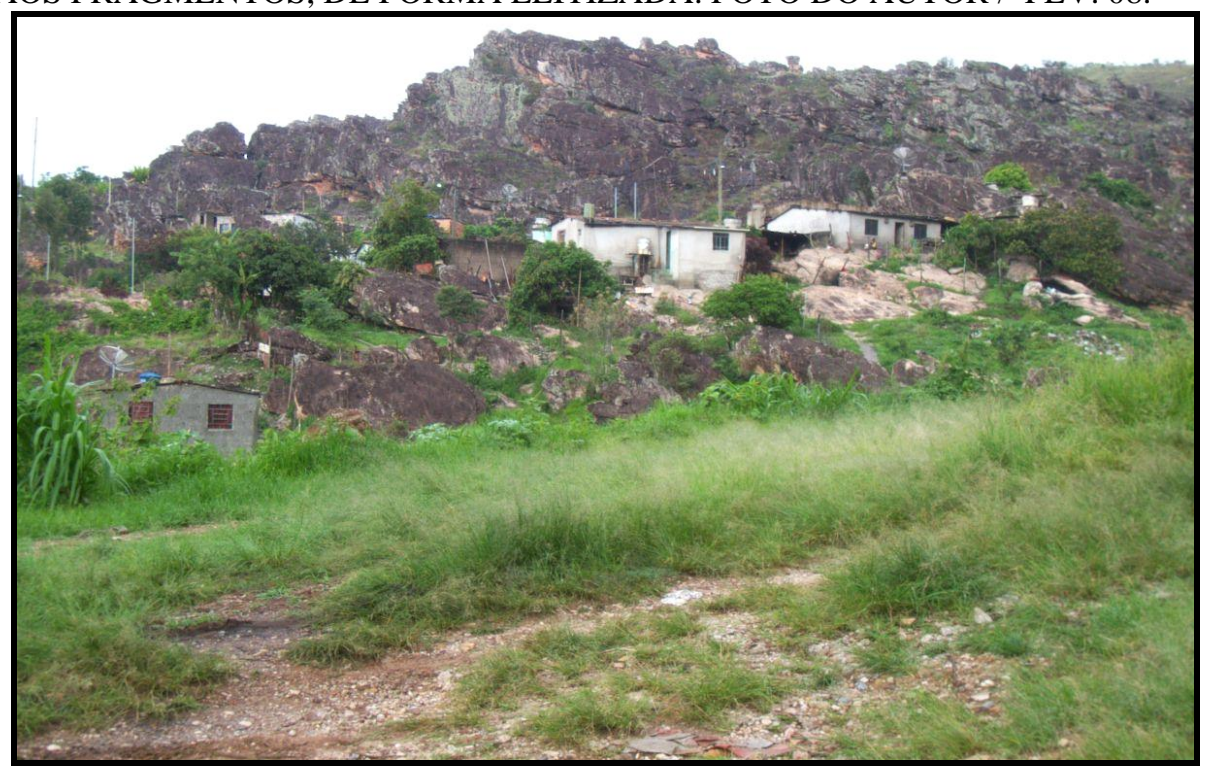


Nessa lógica, a espacialidade aparece como elemento particularizador quando aplicada sobre o próprio processo universal de valorização do espaço; qualifica-o historicamente como o processo singular de formação territorial (MORAES, 2000).

Assim, afirmamos que há uma valorização concentradora em determinados pontos do território, processo que Moraes e Costa (1996) denominam "processo de concentração territorial do capital", que se dá em Diamantina inserida numa totalidade ${ }^{14}$ e enquanto totalidade ${ }^{15}$. Áreas são geradas para representar a aglutinação de objetos do capital, que correspondem às necessidades de replicação e expansão do mesmo, ou seja, concentram-se indústrias, populações, transportes, singularidades, excepcionalidades, "autenticidades" etc., em locais rigorosamente selecionados pelos estrategistas do mercado (caso do centro histórico de Diamantina, em contraponto à sua periferia "precarizada"). Na geopolítica do capitalismo, identificamos que a produção, expansão e conquista de novos espaços vai de encontro a ações humanas mediadas por interesses grupais e classistas, que produzem o "valor do espaço" formando centralidades "ultravaloradas".

Assim, conforme Moraes (2000, p. 38),

Pode-se dizer que a formação territorial é a manifestação empírica da valorização do espaço, da mesma maneira que a formação econômico-social manifesta o modo de produção numa expressão singular. Trata-se de níveis diferenciados de abstração e concreção: o modo de produção e a valorização do espaço referem-se ao plano da universalidade, enquanto as formações mencionadas voltam-se para a esfera da singularidade. A articulação de ambos objetiva a particularidade.

\footnotetext{
${ }^{14}$ Inserida numa totalidade, a cidade é incluída na Lista do Patrimônio Mundial, o que vem a favorecer, hoje, uma "concentração territorial do capital", quando a cidade passa a integrar o circuito internacional do turismo, dada sua reprodução midiática enquanto Patrimônio Cultural da Humanidade.

${ }^{15}$ Considerando a cidade em sua totalidade, não apenas seu centro histórico, identificamos ações público-privadas marcadamente concentradoras do capital, sobretudo a partir de sua consagração como Patrimônio Mundial e da implantação do Programa Monumenta; o problema da fragmentação urbana só é identificada quando da visão total da cidade e não focada em relação ao seu centro histórico, como se a cidade pudesse ser considerada exclusivamente por este. Acreditamos que a análise de uma cidade histórica que não leve em consideração a (re)produção do espaço fora de seu núcleo tombado pode não dar conta do entendimento das novas dinâmicas propiciadas pelas "rugosidades" presentes no próprio centro, que favorecem novos fluxos capazes de transformar a realidade e o imaginário da população residente, não apenas no centro histórico apropriado pelo turismo; uma análise focada e compartimentada pode não dar conta da realidade multidimensional e em movimento da formação de novas espacialidades acarretadas de um novo dinamismo urbano, no âmbito da Geografia.
} 
Por fim, verificamos que se busca na estrutura urbana, na paisagem urbana histórica (UNESCO, 2005, 2007c), a movimentação de investimentos de capital e a formação de um status de serviços terciários capazes de aumentar a atratividade dos bens culturais na área escolhida para o desenvolvimento da atividade turística, na tentativa de se dar mais ênfase a Diamantina no cenário internacional com o turismo cultural. Verifica-se a fetichização das formas, seu "encantamento", a metamorfose de seu valor simbólico em valor econômico, de forma que o consumo estético dos bens culturais passa a ter mais valor do que seu uso social democrático, como aponta Luchiari (2005, p. 99). A municipalidade (com ideologia empresarial) passa a conceber o planejamento aos fragmentos, selecionando áreas que possam atrair o capital, esboçando o que Luchiari chama de "espetacularização do planejamento".

Segundo Luchiari (2005, p. 102), muda-se o conteúdo social dos bens tombados com a vocação turística. Concordamos com a autora ao considerar que as intervenções não são sempre negativas: o problema é dar suma importância às formas e atribuir-lhes um valor econômico em detrimento de seu valor cultural original, destituindo destas paisagens as habitações, os usos pretéritos, o sentimento de pertencimento das populações locais e a sobrevivência das comunidades tradicionais, quando a lógica globalizante (aí entendidas as atividades de lazer e de turismo) organiza de forma específica os espaços dotados de patrimônios culturais, atendendo, preferencialmente, a demandas externas.

Torna-se relevante frisarmos nosso ponto de vista de que seja no turismo ou em qualquer outra "indústria" humana, o que se deve enfatizar não são apenas os bens, sentidos, valores, a permanência ou não da atividade turística, mas a relação estabelecida entre os homens. Seja qual for a atividade desenvolvida por grupos sociais, o que caracterizará a situação social geral, excluídos e beneficiados, são os tipos de interações estabelecidas, julgadas coerentes, aceitáveis e desejáveis, essas sim, ditarão o padrão da sociedade instituída, a fragmentação ou não do espaço urbano, ou a preservação das materialidades e manifestações populares. Nossa crítica se dirige às ações, não aos meios encontrados para espacializá-las, pois esses, em mãos de agentes verdadeiramente comprometidos com a coletividade, podem servir para a edificação de uma 
sociedade menos injusta, mais igualitária e de lugares não-fragmentados, espaços, primordialmente, dos cidadãos. ${ }^{16}$

\section{À GUISA DE UMA CONCLUSÃO: AS CONTRADIÇÕES DO PROCESSO DE "PRESERVAÇÃO" / MERCANTILIZAÇÃO DO PATRIMÔNIO CULTURAL COMO PRODUTOS DA "DIALÉTICA DA CONSTRUÇÃO DESTRUTIVA"}

Neste ponto, não fechamos uma conclusão, mas, ainda, deixamos considerações para a reflexão do leitor, considerações estas que induzem à avaliação do aporte teórico-metodolótico apresentado neste artigo para uma abordagem crítica à mercantilização do patrimônio nas cidades históricas brasileiras, bem como para o entendimento da transformação desses espaços urbanos em sua totalidade.

"Preservação" e mercantilização, valor de uso e valor de troca, cultura e mercadoria, dialeticamente; preserva-se, hoje, para a venda; vende-se o inalienável. É nessa dialética que buscamos entender o jogo de forças dos agentes que produzem o espaço urbano em Diamantina negligenciando a massa da população local, ao se evidenciar uma cidade dual, com um centro em vias de banalização pela "cenarização" progressiva e uma periferia em processo de intensa "precarização".

A abordagem histórico-dialética - método proposto para a análise do processo em tela - é, segundo Kosík (1976, p. 15), o pensamento crítico que se propõe a compreender a "coisa em si" e sistematicamente se pergunta como é possível chegar à compreensão da realidade. Por isso, é o oposto da sistematização doutrinária ou da romantização das representações comuns. Como não nos contentamos com os esquemas abstratos da realidade e suas simples representações do visível, buscamos "destruir a aparente independência do mundo dos contatos imediatos de cada dia" (KOSÍK, 1976, p. 16).

\footnotetext{
${ }^{16}$ Para Becker (1996), o turismo pode se apresentar como um meio de desregulação socioespacial, na falta de um organizador do setor. Posicionamo-nos com a proposição dessa autora, que considera o turismo bem planejado um instrumento criador de um potencial de desenvolvimento, gerador de empregos diretos e indiretos, de circulação de dinheiro, mercadorias e pessoas, mas que em contrapartida, na falta de um adequado planejamento espacial, propicia impactos perversos ao meio ambiente, ao espaço urbano ou mesmo diretamente ao meio social, nos quais se instala.
} 
Nesse sentido, a análise da relação "preservação"/ mercantilização de patrimônio na produção do espaço urbano deve ser direcionada por uma abordagem que desvenda o mundo real para além do mundo da aparência. Por isso, não nos atemos apenas à análise dos novos fluxos e das ações estabelecidas no centro histórico de Diamantina, fato dado que nos fornece a falsa ilusão de um território urbano preservado pela e para a coletividade, mas transcendemos a porção central da cidade e encontramos, na periferia, o que representa a lógica contraditória e perversa da reprodução do capitalismo pela sua própria expansão, uma periferia em processo de intensa "precarização" fruto da seletividade do capital, como nos indica Harvey (2005).

Nesse movimento de destruição do aparente, que Kosík (1976) denomina "pseudoconcreticidade", não negamos a existência ou a objetividade do fenômeno que ronda o centro histórico de Diamantina, mas tentamos destruir sua pretensa independência demonstrando seu caráter derivado. Afirmamos que a inclusão da cidade na Lista do Patrimônio Mundial (ação que representa a universalidade da prática patrimonial) perde o papel principal de valorização cultural, memorial e identitária para se estabelecer como processo que tem na "valorização do espaço" um adendo para a especulação econômica e imobiliária na cidade, apesar de a retórica dos agentes públicos remeterem-nos ao contrário. Confirmamos que esse "evento" redunda em uma política de patrimônio que desvia a atenção pública e recursos de problemas mais amplos, sobretudo, fora do núcleo tombado, o que afeta as condições de vida da população local, transforma o imaginário popular em relação ao seu patrimônio e produz um território urbano, dialeticamente, fragmentado e articulado, quando a "valorização" do centro depende da "precarização" da periferia, esboçando uma cidade dual. A formação de uma cidade dual é o primeiro produto do que denominamos dialética da construção destrutiva que encerra os bens culturais do mundo, no jogo relacional da "preservação" / "mercantilização".

A dialética não considera as configurações e os objetos fixados, como algo originário e independente, como também não considera o mundo das representações banais, não aceita sob o seu aspecto imediato; submete-os a um exame em que as formas reificadas do mundo objetivo e do mundo ideal se diluem, segundo Kosík (1976); perdem a sua fixidez, naturalidade e pretensa originalidade para se mostrarem como fenômenos derivados e mediatos, como sedimentos e produtos da práxis social da humanidade. 
Nesse contexto, fica-nos claro que a "construção" do patrimônio cultural sempre teve um caráter identitário, espacial e político, dialética e universalmente. Primeiro, para afirmação dos "Estados-nações" enquanto símbolos da formação de seus territórios (caráter particularista de patrimônio), depois, no extremo de sua ampliação, na tentativa de se afirmar a diversidade cultural dos povos e a integração das nações, através do conceito de humanidade (caráter universalista do patrimônio). Hoje, o patrimônio passa a ser procurado e encontrado em todo o mundo; adquire uma visibilidade e uma importância inigualáveis na história, englobando tudo o que é dotado de significado cultural irreplicável. Cultura revestida pela lógica da mercadoria, na sociedade contemporânea, fazendo com que o patrimônio, cada vez menos, represente o ideal de "Estado-nação" ou de diversidade cultural dos povos, perdendo, aos poucos, seu referencial de memória viva ao se tornar um produto em potencial do desenvolvimento turístico nos lugares; atividade que tem o poder de banalizar pela cenarização progressiva; isso denota o esvaziamento das práticas de patrimônio, nas cidades históricas. A mercantilização desenfreada dos bens culturais faz com que percam sua função primeira, que é a de esclarecimento, ligada ao valor cognitivo e afetivo, transformando-se num grande fetiche incorporado ao mundo do consumo e se tornando peça central da máquina reprodutiva do capitalismo. Em Diamantina, a prática de patrimônio adotada remete-nos à tendência contemporânea ao "esvaziamento" no campo da cultura. Assim, a minimização do valor simbólico e de uso para a maximização do "capital simbólico" que passa a representar o patrimônio para o habitante local, como atestamos em atividades de campo, é o segundo produto da dialética analisada. São antigas formas que, ao assumirem novas funções, sintetizam novos conteúdos para o residente, dentro da vigente estrutura estabelecida pela reprodução do capitalismo e seletividade do capital, que impactua o território urbano.

Sabendo que as coisas não se mostram ao homem diretamente como são e como o homem não tem a faculdade de ver as coisas na sua essência, Kosík (1976) propõe que a humanidade faça um détour para conhecer as coisas e a sua estrutura. Como tal détour é o único caminho acessível para o homem chegar à verdade sobre os fenômenos - e tal caminho é nebuloso -, periodicamente, poupa-se do trabalho desse desvio e observa diretamente a essência das coisas. Isso significa a tendência à alienação total da humanidade perante os processos que rebatem sobre a cidade enquanto lugar da vida, da morada e das relações sociais. Segundo Kosík (1976, p. 
22), para conhecer as coisas em si, o homem deve primeiro transformá-las em coisas para si; para conhecer as coisas como são independentemente de si, tem primeiro de submetê-las à própria práxis: para poder constatar como são elas quando não estão em contato consigo, tem primeiro de entrar em contato com elas. "O conhecimento não é contemplação (...) o homem só conhece a realidade na medida em que ele cria a realidade humana e se comporta antes de tudo como um ser prático".

Admitimos que a "pseudoalienação" dos agentes públicos em relação à perversidade do mercado e a alienação da população local em relação ao trato despendido à sua cidade e ao seu patrimônio (onde os primeiros - representantes da sociedade e quem deveria ser os defensores das causas coletivas -, contraditoriamente, favorecem a alienação dos segundos) sintetizam a idéia de que o homem, realmente, não se distancia das coisas e de suas estruturas para conhecêlas em essência, daí a importância da teoria e da pesquisa científica compromissada. Logo, identificamos, em Diamantina, uma espécie de "coerção consentida" que simboliza a alienação do residente pela "pseudoalienação" da governança urbana, a qual atinge seus objetivos através da retórica das benesses coletivas advindas da mercantilização do espaço central da cidade. Assim, a simultaneidade entre a ilusão forjada e a "pseudoconcreticidade" do fenômeno - novos fluxos propiciados pelo turismo e vislumbrados pelo morador de Diamantina - promove a alienação do residente por meio de tal coerção consentida, um terceiro produto da dialética da construção destrutiva na consagração do Patrimônio Mundial.

Segundo Milton Santos, em $O$ espaço do cidadão, o espaço tem sido utilizado como veículo do capital e instrumento da desigualdade social, mas uma função diametralmente oposta poderia ser-lhe encontrada. Será impossível chegar a uma sociedade mais igualitária sem reformular a organização do seu espaço. No entanto, deve ser considerado que a dialética da construção destrutiva que envolve o patrimônio cultural, objetivamente, e a cidade histórica, de forma total, é um processo e também um resultado da operacionalização do capital sobre o espaço e sobre os lugares do patrimônio. Nesse contexto, a análise de Diamantina remete-nos à ambivalência do termo valorização; expressão chave para o patrimônio e para o próprio espaço. $\mathrm{O}$ termo que deveria propiciar-nos tranqüilidade, ao contrário, inquieta-nos por sua ambigüidade ao nos remeter a dois estilos de conservação sintetizadas, por um lado, pela valorização simbólica da cultura, por outro - a preponderante -, por sua valorização econômica; essa valorização 
inquieta-nos, também, por identificarmos o valor simbólico do patrimônio servir de adendo para a venda da cidade histórica, um valor de uso civilizatório. Temos desse processo resultante da operacionalização do capital sobre o espaço, o quarto produto da contradição "preservação" / mercantilização dos bens culturais de Diamantina, um planejamento que favorece o antiurbanismo anárquico, um planejamento feito das elites para as elites, um modelo segregacionista de planejamento urbano, quando poderia se constituir em um potencial instrumento de melhoria da qualidade de vida de toda população local e de ordenamento do território urbano enquanto totalidade.

O quinto e último produto identificado do processo contraditório e simultâneo de "preservação" / mercantilização operacionalizado em Diamantina é a tendência ao "fim" da cidade histórica, é o caso limite de uma crise que não ameaça apenas a paisagem urbana histórica, o figurino dessas cidades simbólicas (o que denominamos urbanismo barroco das Geraes), mas a instituição urbana em si; o processo mercantil em curso minimiza o significado da cidade histórica como embrião, sede e centro do processo civilizatório brasileiro; a lógica mercantil em tela minimiza a própria concepção de espaço como dimensão cultural da vida social, para se tornar palco de atuação do capital.

Nesta perspectiva, o aporte teórico-metodológico apresentado neste artigo favorece a olharmos, criticamente, para o conteúdo que refuncionaliza o patrimônio e lhe atribui novos valores que são retratados no imaginário do residente; tentamos identificar a segregação socioespacial evidente a partir da "valorização do espaço" no centro histórico, bem como desvendar os usos que cercam esse espaço central em favor da "precarização" da periferia. Consideramos, assim, que a partir da teoria crítica sobre a "valorização do espaço" podemos desnudar a "pseudoconcreticidade" latente que ronda a cidade histórica com o turismo que reproduz o espaço urbano à sua lógica.

Principalmente por estar em sua forma embrionária, em Diamantina, acreditamos que o processo contraditório de "preservação" / mercantilização de patrimônio para a atividade do turismo deve ser acompanhado - de perto e sob orientação - por seus verdadeiros donos, o habitante local. Deve-se promover, de forma equilibrada e coletiva, a valorização cultural e mesmo econômica dos lugares do patrimônio, desde que seja a vontade e a necessidade da maioria. Não buscamos santificar ou bestializar o mercado, muito menos o turismo, mas propor a 
busca de soluções socioespaciais democráticas através da gestão participativa dos bens culturais do mundo (UNESCO, 2007b) e da implementação de Políticas Públicas de Educação Patrimonial; as quais devem estar centradas, por meio das diversas instituições de ensino, nas crianças e nos adolescentes, os futuros guardiões do patrimônio cultural e natural do mundo. Para tanto são de suma referência as diretrizes das várias cartas patrimoniais editadas ao longo do século XX e no início deste século, como a Carta de Veneza (1964), a Carta de Quito (1967), a Convenção do Patrimônio Mundial (1972), a Declaração de Amsterdã (1975), a Recomendação de Nairóbi (1976) e o Memorando de Viena (2005).

Militamos não pelo fim da dinâmica econômica e turística nesses espaços, as quais podem sim, contribuir para melhoria das condições de vida da população local a partir de uma gestão verdadeiramente participativa da cidade histórica, mas defendemos a permanência dos usos sociais tradicionais e contemporâneos, harmoniosamente, nesses espaços coletivos da história, da memória e da cultura, de forma a não se produzirem territórios urbanos fragmentados. Militamos pela "sobrevivência" da cidade histórica (enquanto totalidade perpassada pela lógica capitalista de um mercado global) e pela "perpetuação" de seus habitantes, ante um mundo que se mostra cada vez mais voraz.

Por fim, dessa forma, deixando de isolar os fatos e os fenômenos, como propõe o método dialético, devemos reintegrá-los em seu movimento: movimento interno, que provém deles mesmos, e movimento externo, que os envolve no devir universal. Os dois movimentos são inseparáveis (LEFEBVRE, 1975, p. 238). Só a partir de um instrumento que capte a ligação, a unidade e o movimento que engendra as ações contraditórias, que as opõe, que faça com que se choquem, que as supere, podemos superar a ilusão da realidade; esse instrumento é a busca do conhecimento que não se limita à contemplação. $\mathrm{O}$ homem só conhece a realidade quando cria a realidade humana e se comporta como um ser não-alienado, prático e revolucionário. Logo, a cidade histórica deve se estabelecer como o espaço de um homem desalienado, um espaço em que todos se unam para o trabalho e não se separem em classes antagônicas conflitantes; a cidade histórica só se estabelecerá como um espaço coletivo, de toda gente, quando a luta for pelo resgate de seu valor de uso civilizatório em detrimento ao seu valor de troca tão em voga. A teoria deve favorecer esta prática. 
Falta o discurso coerente da cidade, pois o discurso incoerente, fragmentado e analiticamente indigente, já existe. Os próprios intelectuais ainda buscam as variáveis adequadas para escrever essa pedagogia do urbano que codifique e difunda, em termos didáticos e de maneira simples, o emaranhado de situações e relações com que o mundo da cidade transforma o homem urbano em instrumento de trabalho e não mais em sujeito. Entretanto, todos os dados estão praticamente em nossas mãos, para tentar reverter a situação (...) Ficar prisioneiro do presente ou do passado é a melhor maneira para não fazer aquele passo adiante, sem o qual nenhum povo se encontra com o futuro. (SANTOS, 2007, p. 161, grifos nossos).

\section{REFERÊNCIA BIBLIOGÁFICA}

BECKER, Bertha. Políticas e Planejamento do Turismo no Brasil. In: YÁZIGI, E. CARLOS, A. F. A. CRUZ, R.C.A. (orgs). Turismo: Espaço, Paisagem e Cultura. São Paulo: Editora Hucitec, 1996.

CIFELli, Gabrielle. Turismo, Patrimônio e Novas Territorialidades em Ouro Preto - MG. Campinas: UNICAMP/ Dissertação de Mestrado - Instituto de Geociências, 2005.

COSTA, Everaldo. B. Turismo, comércio e patrimônio em São João Del Rei-MG. In: Colóquio Internacional sobre o Comércio e a Cidade, n. 2, 2008, São Paulo. Anais do Colóquio (FAU / USP), 2008.

COSTA, Everaldo B; CASTRO, Bernadete C. O processo de "banalização pela cenarização" em núcleos urbanos tombados: o caso de Tiradentes - MG. Belo Horizonte: Revista Geografias / IGC / UFMG, 2008a.

COSTA, Everaldo Batista. A dialética da construção destrutiva na consagração do Patrimônio Mundial. Rio Claro (SP) / Revista Olam: Ciência e Tecnologia, Vol. 8, n 1, 2008b.

COSTA, Everaldo Batista. A dialética da construção destrutiva na consagração do Patrimônio Mundial: o caso de Diamantina (MG). São Paulo: DG / USP, Dissertação de Mestrado - FFLCH, 2009.

CRUZ, Rita de C. A. Introdução à Geografia do Turismo. São Paulo: ROCA, 2003.

CRUZ, Rita de C. A. Geografias do Turismo: de Lugares a Pseudo-lugares. São Paulo: ROCA, 2007.

HARVEY, David. A justiça social e a cidade. São Paulo: Editora Hucitec, 1980.

HARVEY, David. A produção capitalista do espaço. São Paulo: Annablume, 2005.

KOSÍK, Karel. Dialética do Concreto. Rio de Janeiro: Ed. Paz e Terra, 1976.

LEFEBVRE, Henri. Lógica formal / lógica dialética. Rio de Janeiro: Editora Civilização Brasileira, 1975. 
LEITE, Rogério Proença S. Contra-Usos da Cidade: Lugares e Espaço Público na Experiência Urbana Contemporânea. Campinas, SP: Editora da UNICAMP; Aracaju, SE: Editora da UFS, 2004.

LUCHIARI, Maria T. D.P. A reinvenção do patrimônio arquitetônico no consumo das cidades. São Paulo: GEOUSP - Espaço e Tempo, n 17, 2005.

MARX, Karl. O Capital: Crítica da Economia Política; Livro 1, vol 1. São Paulo: Difel, 1982.

MORAES, Antônio Carlos Robert. Geografia Crítica: A Valorização do Espaço. São Paulo. Editora HUCITEC, 1993.

MORAES, A. C. R; COSTA, W. M. A geografia e o processo de valorização do espaço. In: SANTOS, M. (org.). Novos rumos da geografia brasileira. Editora Hucitec, 1996.

MORAES, Antônio Carlos Robert. Capitalismo, Geografia e Meio Ambiente. São Paulo: Tese de Livre Docência. FFLCH/USP, 2000.

MORAES, Antônio Carlos Robert. Meio Ambiente e Ciências Humanas. São Paulo. Editora Annablume, 2005.

SANTOS, Milton. Espacio y Método. Barcelona (Espanha). GeoCrítica (Universidad de Barcelona), 1986.

SANTOS, Milton. A natureza do espaço: técnica, tempo, razão e emoção. São Paulo: Editora da Universidade de São Paulo (Edusp), 2002.

SANTOS, Milton. Por uma geografia nova. São Paulo: EdUSP, 2004.

SANTOS, Milton. Pensando o Espaço do Homem. São Paulo: Editora da Universidade de São Paulo (Edusp), 2004a.

SANTOS, Milton. O espaço do cidadão. São Paulo: EdUSP, 2007.

SCARLATO, Francisco C. Revitalização do Centro Antigo: O Espaço da Memória de São Paulo. In: CARLOS, A. F. CARRERAS, C. Urbanização e Mundialização: estudos sobre a metrópole. São Paulo: Editora Contexto, 2005.

SCARLATO, Francisco C. População e Urbanização Brasileira. In: ROSS, J. (org.) Geografia do Brasil. São Paulo: Editora da Universidade de São Paulo (Edusp), 2005a.

SCIFONI, Simone. Patrimônio Mundial: do ideal humanista à utopia de uma nova civilização. São Paulo. Revista Geousp - Espaço e Tempo, n ${ }^{\circ}$ 14, 2003.

SILVA, Fernando F. As Cidades Brasileiras e o Patrimônio Cultural da Humanidade. São Paulo: Editora da Universidade de São Paulo (Edusp), 2003.

THOMPSON, John B. Ideologia e cultura moderna: teoria social crítica na era dos meios de comunicação de massa. Rio de Janeiro, Ed. Vozes, 1995. 
Revista Geografar

Curitiba, v.3, n.2, p.34-58, jul./dez. 2008 www.ser.ufpr.br/geografar

ISSN: 1981-089X

\section{DOCUMENTOS INTERNACIONAIS}

UNESCO. Convention concernant La Protection Du Patrimoine Mondial Culturel Et Naturel. Adoptée par la Conférence générale à sa dix-septième sessiona. Paris, Siège de l'UNESCO, 1972.

UNESCO. Adoption de la Déclaration sur la conservation des paysages urbains historiques. Le patrimoine mondial et l'architecture contemporaine - Gestion du paysage urbain historique. Paris, Siège de l'UNESCO, 2005.

UNESCO. Discussion sur la valeur universelle exceptionnelle. Paris, 2007.

UNESCO. Liste des Etats parties la Convention du patrimoine mondial, Répartition des biens du patrimoine mondial dans les Etats parties et Composition du Comitê du patrimoine mondial depuis 1976. Paris, Siège de l’UNESCO, 2007a.

UNESCO. Plans de gestion et protection, outils de conservation et de promotion des biens du patrimoine mondial. Paris, Siège de l'UNESCO, $2007 \mathrm{~b}$.

UNESCO. Rapport sur l'élaboration d'une recommandation révisée sur a consevation des paysages urbains historiques. Paris, Siège de l'UNESCO, 2007c.

(Recebido em dezembro/08. Aceito em janeiro/09) 